\title{
Agents Protecting against Sepsis from the Roots of Angelica dahurica
}

\author{
Dong-Keun Song, ${ }^{a}$ Ji-Yeon KIM, ${ }^{b}$ Gao Li, ${ }^{b, c}$ Kyeung-Seon LeE, ${ }^{b}$ Chang-Seob Seo, ${ }^{b}$ Ji-Jing YAn, ${ }^{a}$ \\ Jun-Sub Jung, ${ }^{a}$ Hyo-Jin KIM, ${ }^{b}$ Hyun-Wook ChAng, ${ }^{b}$ and Jong-Keun Son $*, b$ \\ ${ }^{a}$ Department of Pharmacology, Hallym University College of Medicine, Institute of Natural Medicine; Chunchon 200-702, \\ Republic of Korea: ${ }^{b}$ College of Pharmacy, Yeungnam University; Gyongsan 712-749, Republic of Korea: and ${ }^{c}$ College of \\ Pharmacy, Yanbian University; Yanji 133000, P.R. China. Received August 9, 2004; accepted October 12, 2004
}

\begin{abstract}
In the course of isolating agents preventing sepsis from the EtOAc extract of the roots of Angelica dahurica, four known furanocoumarins, isoimperatorin (1), oxypeucedanin (2), ( \pm )-byakangelicin (3), and (+)oxypeucedanin hydrate (4), were isolated as active compounds based on the in vivo assay model of sepsis induced by lipopolysaccharide (LPS) and D-galactosamine (D-GalN). Among them, 3 showed the highest survival rate $(100 \%$ with a dose of $30 \mathrm{mg} / \mathrm{kg}$ versus $20 \%$ for the control experiment) and decreased the plasma levels of tumor necrosis factor- $\alpha$ and alanine aminotransferase in mice adminstered LPS/D-GalN.
\end{abstract}

Key words Angelica dahurica; sepsis; lipopolysaccharide; furanocoumarin; tumor necrosis factor- $\alpha$; alanine aminotransferase

Sepsis is a clinical syndrome frequently induced by lipopolysaccharide (LPS), which is one of the major cell wall components of gram-negative bacteria and stimulates immunocytes, mainly macrophages, to release endogenous mediators such as tumor necrosis factor (TNF)- $\alpha$, interleukin (IL)-1, IL-6, IL-10, prostanoids, leukotrienes, and nitric oxide. ${ }^{1,2}$ These mediators frequently result from excessive stimulation of the host immune system through complex signal transductions and lead to hypotension and multiorgan dysfunction with a high mortality rate. ${ }^{1,2)}$ In patients with sepsis, TNF- $\alpha$ plays a major role in the associated systemic toxicity. ${ }^{3)}$ Loss of hepatic function is one of the hallmarks of the development of multiple-organ failure associated with severe sepsis. ${ }^{4,5)}$ There have been reports that the synthetic compounds IRFI $042,{ }^{6}$ tyrphostin AG $126,{ }^{7}$ and SR $27388^{8)}$ show significant protection against lethality due to septic shock, and lysophosphatidylcholine (LPC) can effectively prevent and treat sepsis and microbial infections. ${ }^{9}$ Recently, protective compounds against sepsis have been reported from

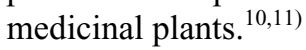

The protective activity against sepsis-induced lethality of the methanol extracts of about 100 Korean medicinal plants was determined based on the sepsis model induced by lipopolysaccharide/D-galactosamine, from which Angelica dahurica (Umbelliferae) was chosen as one of the active plants. The roots of $A$. dahurica have been used in Korean folk medicine as an antipyretic and analgesic for colds. ${ }^{12)}$ Biological activities of the components from this plant, such as hepatoprotective activity against tacrine-induced cytotoxicity in Hep G2 cells, ${ }^{13)}$ inhibition of compound 48/80-induced histamine release in the mouse peritoneal cavity, ${ }^{14)}$ antimicrobial activity, ${ }^{15)}$ and affinity to brain benzodiazepine receptors in vitro, ${ }^{16)}$ have been reported. In this paper, the isolation and activity of four known furanocoumarins as antiseptic shock agents from the roots of this plant are described.

\section{MATERIALS AND METHODS}

General Procedures Melting points were measured using a Fisher-Johns melting point apparatus and are uncorrected. Optical rotations were measured using a JASCO DIP1000 (Tokyo, Japan) automatic digital polarimeter. The
NMR spectra were recorded on Bruker $250-\mathrm{MHz}$ (DMX 250), and Bruker 300-MHz (ARX 300) spectrometers. Samples were dissolved in either chloroform- $d_{1}$ or $\mathrm{CD}_{3} \mathrm{OD}-d_{4}$, and chemical shifts are reported in ppm downfield from TMS. The two-dimensional NMR spectra were recorded using Bruker's standard pulse program. The FAB-MS spectra were measured with a VG TRIO $2 \mathrm{~A}$ mass spectrometer. Silica gel 60 (70-230 and 270 - 400 mesh), reverse-phase support (LiChroprep RP-18) and TLC plates (Si-gel $60 \mathrm{~F}_{254}$ ) were purchased from Merck KGaA (Darmstadt, Germany). Spots were detected under UV radiation and by spraying with $10 \% \mathrm{H}_{2} \mathrm{SO}_{4}$, followed by heating. Dexamethasone was purchased from Sigma Chemical (St. Louis, MO, U.S.A.). All other chemicals solvents were of analytical grade and used without further purification.

Plant Material Dried roots of $A$. dahurica Bentham et HOOKER were purchased in November 1997 from Yak-ryongsi the folk medicine market in Daegu, and the material was confirmed taxonomically by Professor Ki-Hwan Bae, Chungnam National University, Daejeon, Republic of Korea. A voucher specimen (YNS-97-01) is deposited at the College of Pharmacy, Yeungnam University.

Extraction and Isolation The dried roots of $A$. dahurica $(10 \mathrm{~kg})$ were extracted twice with $70 \% \mathrm{MeOH}(201)$ under reflux for $12 \mathrm{~h}$. The $\mathrm{MeOH}$ solution was evaporated to dryness $(3 \mathrm{~kg})$ and the residue partitioned between $\mathrm{H}_{2} \mathrm{O}(11)$ and hexane $(3 \times 11)$. The resulting $\mathrm{H}_{2} \mathrm{O}$ layer was extracted with EtOAc $(3 \times 11)$ and $n$ - $\mathrm{BuOH}(3 \times 11)$ successively. The resulting solutions were evaporated to dryness to give $n$-hexane, EtOAc, $n$-BuOH, and $\mathrm{H}_{2} \mathrm{O}$ extracts $(711 \mathrm{~g}, 36 \mathrm{~g}, 128.9 \mathrm{~g}$, and $1800 \mathrm{~g}$, respectively). The EtOAc extract $(35.8 \mathrm{~g})$ was chromatographed on a silica gel column $(230-400$ mesh, $6.5 \times 45 \mathrm{~cm}$ ) to give 16 fractions (Fr. 1-Fr. 16) with hexane-EtOAc (gradient from 2:8 to $100 \%$ EtOAc) and EtOAc- $\mathrm{MeOH}$ (gradient from $100 \%$ EtOAc to $100 \%$ $\mathrm{MeOH})$. Fr. 1 (543 mg) was recrystallized from hexaneEtOAc $(6: 4)$ to give isoimperatorin $(1,380 \mathrm{mg}$, pale yellow crystal, mp $\left.104-106^{\circ} \mathrm{C}\right) .{ }^{17)}$ Fr. $4(600 \mathrm{mg})$, Fr. $10(1.97 \mathrm{~g})$, and Fr. $11(3 \mathrm{~g})$ were separately recrystallized from EtOAc to give $( \pm)$-oxypeucedanin $[2,436 \mathrm{mg}$, white amorphous powder, mp $138-140^{\circ} \mathrm{C},[\alpha]_{\mathrm{D}}^{20}+1.5^{\circ}\left(c, 0.225\right.$ in $\left.\left.\left.\mathrm{CHCl}_{3}\right)\right]\right]^{13,18,19)}$ (士)-byakangelicin $[3,900 \mathrm{mg}$, pale yellow amorphous pow- 


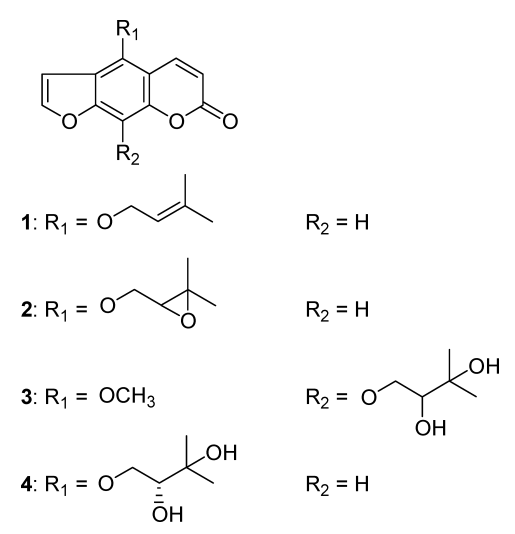

Fig. 1. Compounds Purified from the Roots of Angelica dahurica

der, mp $122-124^{\circ} \mathrm{C},[\alpha]_{\mathrm{D}}^{20}+4.4^{\circ}(c, 0.45$ in $\left.\mathrm{MeOH})\right],{ }^{13,20)}$ and $(+)$-oxypeucedanin hydrate $[4,920 \mathrm{mg}$, yellow amorphous powder, mp $131-133^{\circ} \mathrm{C} ;[\alpha]^{20}+7.9^{\circ}(c, 0.375$ in acetone) $],{ }^{17,20,21)}$ respectively. The structures of the four compounds are shown in Fig. 1.

Animals and Reagents Male ICR mice weighing 23$28 \mathrm{~g}$ (Myung-Jin, Inc., Seoul, South Korea) were housed 5 per cage in a room maintained at $22 \pm 1{ }^{\circ} \mathrm{C}$ with an alternating 12-h light-dark cycle. Food and water were available $\mathrm{ad}$ libitum. LPS (Escherichia coli 055: B5, Sigma) was dissolved in phosphate-buffered saline (PBS, pH 7.2) $1 \mu \mathrm{g} / \mu \mathrm{l}$ and stored at $-80^{\circ} \mathrm{C}$ until use. D-GalN (ICN, U.S.A.) was dissolved in PBS $0.16 \mathrm{~g} / \mathrm{ml}$ and added to $7.2 \mu \mathrm{l}$ of LPS solution. The LPS/D-GalN mixture was used immediately. Each mouse received LPS/D-GalN (LPS $36 \mu \mathrm{g} / \mathrm{kg}$, D-GalN $0.8 \mathrm{~g} / \mathrm{kg}$ ) intraperitoneally at volume of $1 \mathrm{ml} / 100 \mathrm{~g}$ body weight. Solvent extracts and purified compounds of the plant were dissolved in $10 \%$ DMSO. Dexamethasone (3, 5, $10 \mathrm{mg} / \mathrm{kg}$ ) was used for the positive control experiment.

LPS/D-GalN-Induced Lethality and Cytokine Measurements Mice were injected intraperitoneally with crude solvent extracts or purified compounds of the plant or vehicle $30 \mathrm{~min}$ before intraperitoneal injection of LPS/D-GalN. The survival rate was recorded once daily for up to $3 \mathrm{~d}$. For cytokine measurements, blood was collected at various time points $(0,1.5,3,6 \mathrm{~h})$ after $\mathrm{LPS} / \mathrm{D}-\mathrm{GalN}$ administration from the retroorbital venous plexus and centrifuged at $4000 \mathrm{rpm} \times 15 \mathrm{~min}$ at $4{ }^{\circ} \mathrm{C}$. Plasma samples were stored at $-20^{\circ} \mathrm{C}$ until assayed. Plasma levels of TNF- $\alpha$, IL-6, and IL10 were measured with an enzyme-linked immunoassay kit (Genzyme, U.S.A.). The sensitivity limits of TNF- $\alpha$, IL-6, and IL-10 were $3 \mathrm{pg} / \mathrm{ml}, 3 \mathrm{pg} / \mathrm{ml}$ and $13 \mathrm{pg} / \mathrm{ml}$, respectively. Assays were performed exactly as described by the manufacturer.

Alanine Aminotransferase Analysis Liver damage was evaluated by measuring plasma alanine aminotransferase activity using an ALT kit (Yeongdong Pharmaceutical Corp., Seoul, Korea) according to the Reitman-Frankel method. Mice were pretreated with crude extracts intragastrically or with purified compounds of this plant intraperitoneally $30 \mathrm{~min}$ before injection of D-galN $(800 \mathrm{mg} / \mathrm{kg})$ and LPS $(36 \mu \mathrm{g} / \mathrm{kg})$. Blood $(400 \mu \mathrm{l})$ was collected $6 \mathrm{~h}$ after injection of D-galN and LPS by puncturing the retroorbital venous plexus. Plasma was separated by centrifuging at $400 \mathrm{rpm}$. Plasma samples were diluted to $1: 20$ with saline prior to
Table 1. Effects of Solvent Extracts on LPS/D-GalN-Induced Lethality in Mice

\begin{tabular}{cccccc}
\hline \hline & Control & Hexane & EtOAc & $n$-BuOH & $\mathrm{H}_{2} \mathrm{O}$ \\
\hline Survival rate $^{a)}$ & $0 / 5$ & $0 / 5$ & $3 / 5$ & $3 / 5$ & $1 / 5$ \\
\hline
\end{tabular}

a) Number of live mice/number of total mice. Mice were injected intraperitoneally with a dose of $100 \mathrm{mg} / \mathrm{kg}$ of solvent extracts of the plant or vehicle $30 \mathrm{~min}$ before intraperitoneal injection of LPS/D-GalN. The survival rate was recorded once daily for up to $3 \mathrm{~d}$.

Table 2. Effects of the Purified Compounds on LPS/D-GalN-Induced Lethality in Mice

\begin{tabular}{clllll}
\hline \hline Dose $(\mathrm{mg} / \mathrm{kg})$ & $\mathbf{1}$ & $\mathbf{2}$ & $\mathbf{3}$ & $\mathbf{4}$ & Dexamethasone $^{b)}$ \\
\hline Control & $1 / 5^{a)}$ & $1 / 5$ & $1 / 5$ & $0 / 5$ & $1 / 5$ \\
3 & $1 / 5$ & $1 / 5$ & $2 / 5$ & $1 / 5$ & $3 / 5$ \\
10 & $2 / 5$ & $2 / 5$ & $4 / 5$ & $1 / 5$ & $5 / 5$ \\
30 & $1 / 5$ & $2 / 5$ & $5 / 5$ & $2 / 5$ & $5 / 5$ \\
\hline
\end{tabular}

a) Number of live mice/number of total mice. b) Dexamethasone: positive control. Mice were injected intraperitoneally with various doses of the purified compounds from the plant or vehicle $30 \mathrm{~min}$ before intraperitoneal injection of LPS/D-GalN. The survival rate was recorded once daily for up to $3 \mathrm{~d}$.

ALT measurement. Assays were performed exactly as described by the manufacturer.

Statistical Analysis Statistical analysis was carried out using one-way analysis of variance (ANOVA). Bonferroni and Newman-Keuls tests were used for post-hoc comparisons. Probability $(p)$ values of less than 0.05 were considered to indicate statistical significance.

\section{RESULTS AND DISCUSSION}

The $\mathrm{MeOH}$ extract of the roots of $A$. dahurica was partitioned successively with hexane, EtOAc, $n$ - $\mathrm{BuOH}$, and $\mathrm{H}_{2} \mathrm{O}$ and then dried. When each of these solvent extracts $(100 \mathrm{mg} / \mathrm{kg})$ was pretreated with the LPS/D-GalN-induced lethality model, the groups of mice pretreated with the EtOAc and $n$-BuOH extracts showed increased survival rates ( 3 of 5 mice) compared with the control experiment in which all 5 mice died (Table 1). The EtOAc extract was further chromatographed on a silica gel column and major column fractions were recrystallized, which afforded isoimperatorin (1), oxypeucedanin (2), (士)-byakangelicin (3), and (+)oxypeucedanin hydrate (4).

Their structures were identified by comparison of optical rotations, ${ }^{1} \mathrm{H}$ - and ${ }^{13} \mathrm{C}-\mathrm{NMR}$, DEPT, and MS data with the reported ones of the corresponding compounds. ${ }^{13,17-21)}$ Among the purified compounds, 3 showed the strongest protective effect against lethality induced by LPS/D-GalN (Table 2). Pretreatment of mice with 3 at doses of 3, 10, and $30 \mathrm{mg} / \mathrm{kg}$ increased survival rates to $40 \%, 80 \%$, and $100 \%$, respectively, compared with $20 \%$ in the control experiment, while pretreatment with dexamethasone as a positive control at doses of 3,10 , and $30 \mathrm{mg} / \mathrm{kg}$ increased survival rates to $60 \%, 100 \%$, and $100 \%$, respectively. As an initial mechanistic study, levels of TNF- $\alpha$, IL-6, and IL-10 in plasma samples from mice treated with $3(30 \mathrm{mg} / \mathrm{kg})$ were measured and compared with those of the control LPS/D-GalN group (Fig. 2). One and one-half hours after treatment with LPS/D-GalN, the level of TNF- $\alpha$ in plasma samples of mice pretreated with $3(30 \mathrm{mg} / \mathrm{kg})$ was 5 -fold lower than that in the control 


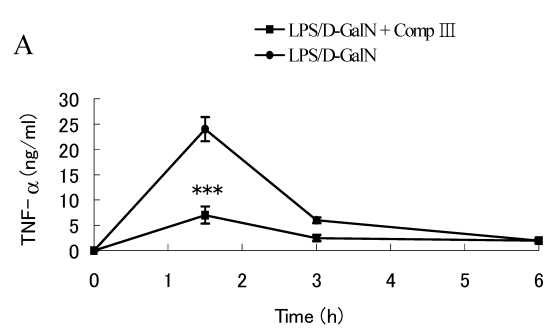

B

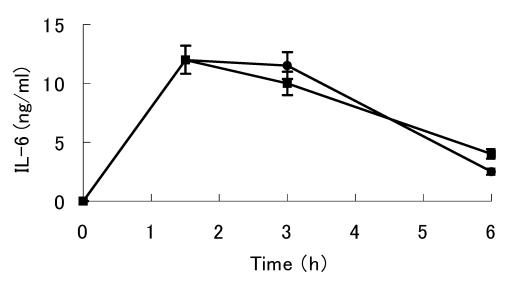

C

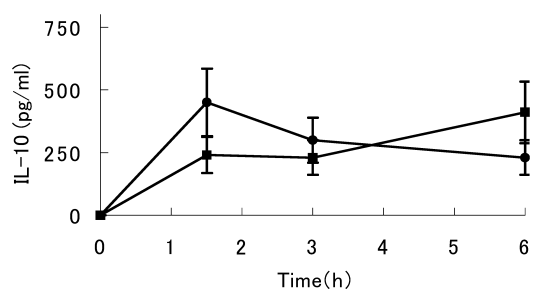

Fig. 2. Effect of $3(30 \mathrm{mg} / \mathrm{kg})$ on Plasma TNF- $\alpha$ (A), IL-6 (B), and IL-10 (C) Levels at Various Time Points after Intraperitoneally Administration of LPS $(36 \mu \mathrm{g} / \mathrm{kg}) / \mathrm{D}-\mathrm{GalN}(0.8 \mathrm{~g} / \mathrm{kg})$

Data are mean \pm S.E.M. of 5 to 7 mice. $* * * p<0.001$ significant difference from LPS/D-GalN-treated group at the time point.

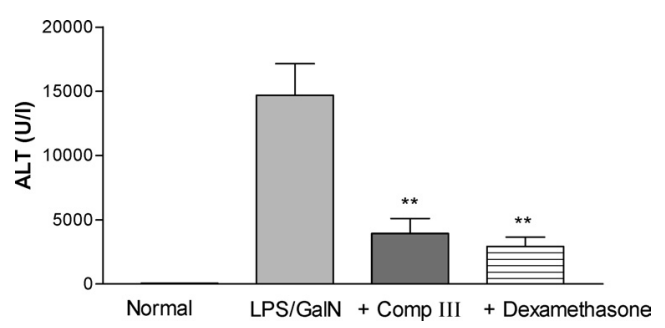

Fig. 3. Effects of Preteatment with $3(30 \mathrm{mg} / \mathrm{kg})$ on the Increase in Plasma ALT Levels $6 \mathrm{~h}$ after Intraperitoneal Administration of LPS/D-GalN

Data are mean \pm S.E.M. of 5 to 7 . $* * p<0.01$ significant difference from LPS/DGalN-treated group. Dexamethasone $(10 \mathrm{mg} / \mathrm{kg})$, positive control.

LPS/D-GalN-treated group. However, no significant changes in levels of IL-6 and IL-10 after pretreatment with 3 were observed. To investigate the effects of $\mathbf{3}$ on liver damage due to LPS/D-GalN administration in mice, ALT values were measured. The effects were almost the same as those of dexamethasone with more than $70 \%$ reduction of ALT activity in plasma samples of mice pretreated with $3(30 \mathrm{mg} / \mathrm{kg})$ compared with that of the control LPS/D-GalN-treated group (Fig. 3).

In conclusion, 3 at a dose of $30 \mathrm{mg} / \mathrm{kg}$ completely pro- tected mice from LPS/D-GalN induced death. In the initial mechanistic study, 3 showed inhibitory activity against LPS/D-GalN induced plasma levels of TNF- $\alpha$ but did not affect IL-6 and IL-10 levels and exhibited hepatoprotective activity. These results suggest that the protective effect of 3 against LPS/D-GalN induced lethality may occur through downregulation of TNF- $\alpha$ and hepatoprotection. The purification of other active compounds from the $n$ - $\mathrm{BuOH}$ extract of this plant is in progress.

Acknowledgments This research was financially supported by a Korean Research Foundation Grant (KRF-2002005-E00019).

\section{REFERENCES}

1) Wakabayashi G., Gelfand J. A., Jung W. K., Connolly R. J., Burke J. F., Dinarello C. A., J. Clin. Invest., 87, 1925-1935 (1991).

2) Zhang H., Peterson J. W., Niesel D. W., Klimpel G. R., J. Immunol., 159, $4868-4878$ (1997).

3) Deitch E. A., Shock, 9, 1-11 (1998).

4) Wang P., Chaudry I. H., Am. J. Physiol., 270, R927-938 (1996).

5) Bone R. C., Balk R. A., Cerra F. B., Dellinger R. P., Fein A. M., Knaus W. A., Schein R. M., Sibbald W. J., Chest, 101, 1644-1655 (1992).

6) Altavilla A., Squadrito G., Minutoli L., Deodato B., Bova A., Sardella A., Seminara P., Passaniti M., Urna G., Venuti S. F., Caputi A. P., Squadrito F., Cardiovas. Res., 54, 684-693 (2002).

7) Novogrodsky A., Vanichkin A., Patya M., Gazit A., Osherov N., Levitzki A., Science, 264, 1319-1332 (1994).

8) Herbert J. M., Fraisse L., Bachy A., Valette G., Savi P., Laplace M. C., Lassalle J., Roche B., Lale A., Keane P. E., J. Lipid Mediat., 8, 31-51 (1993).

9) Yan J. J., Jung J. S., Lee J. E., Lee J., Huh S. O., Kim H. S., Jung K. C., Cho J. Y., Nam J. S., Suh H. W., Kim Y. H., Song D. K., Nat. Med., 10, 161-167 (2004).

10) Lee S. W., Li G., Lee K. S., Jung J. S., Xu M. L., Seo C. S., Chang H. W., Kim S. K., Song D. K., Son J. K., Planta Med., 69, $861-864$ (2003).

11) Kawaguchi K., Kikuchi S., Hasunuma R., Maruyama H., Ryll R., Kumazawa Y., Planta Med., 70, 17-22 (2004).

12) Kim C. M., Kwon Y. S., Yun-Choi H. S., Kor. J. Pharmacogn., 26, $74-77$ (1995).

13) Oh H., Lee H. S., Kim T., Chai K. Y., Chung H. T., Kwon T. O., Jun J. Y., Jeong O. S., Kim Y. C., Yun Y. G., Planta Med., 68, 463464 (2002).

14) Kimura Y., Okuda H., J. Nat. Prod., 60, 249-251 (1997).

15) Kwon Y. S., Kobayashi A., Kajiyama S., Kawazu K., Kanzaki H., Kim C. M., Phytochemistry, 44, 887-889 (1997).

16) Bergendorff O., Dekermendjian K., Nielsen M., Shan R., Witt R., Ai J., Sterner O., Phytochemistry, 44, 1121-1124 (1997).

17) Baek N. I., Ahn E. M., Kim H. Y., Park Y. D., Arch. Pharm. Res., 5, $467-470$ (2000).

18) Hata K., Kozawa M., Yen K., Yakugaku Zasshi, 83, 606-610 (1963).

19) Harkar S., Razdan T. K., Waight E. S., Phytochemistry, 23, 419-426 (1984).

20) Ryu S. H., Kou N. Y., Choi H. S., Ryu H., Kim T. S., Kim K. M., Planta Med., 67, 172-174 (2001).

21) Ishihara K., Fukudake M., Takayuki A., Mizuhara Y., Wakui Y., Yanagisawa T., Kamei H., Ohmori S., Kitada M.,. J. Chromatogr. B, 753, 309-314 (2001). 